\title{
AUTOBIOGRAFIAS E A POSSIBILIDADE DE UMA CENA ENGAJADA: AS EXPERIÊNCIAS DE PROYECTO PROMETEU E TESTIGO DE LAS RUÍNAS DO GRUPO MAPA TEATRO
}

\section{Resumo}

O presente trabalho se propõe a refletir sobre a exploração de dinâmicas artísticas que se estabelecem nas fronteiras entre ficção e realidade, a partir da experiência teatral Proyecto Prometeu e Testigo de Las Ruínas, coordenada pelo grupo colombiano Mapa Teatro. Pretendemos estabelecer, assim, ponderações acerca dos pressupostos estéticos e éticos inscritos nessas propostas teatrais, que tiveram como mote de criação levantar discussões referentes à desapropriação que vinham sofrendo moradores do, hoje extinto, bairro Santa Inês a partir das impressões, lembranças e relatos pessoais desses antigos moradores. O presente trabalho concentra sua análise especificamente nos modos e objetivos do uso de autobiografias dos antigos moradores na construção das ações cênicas desses espetáculos.

Palvras-chave: Mapa Teatro. Ficção. Autobiografia. Teatro Documentário. Memória.

\section{Heloisa Marina da Silva * Stephan A Baumgärtel **}

\section{Abstract}

This paper presents a reflection on the artistic dynamics that are established at the boundaries between fiction and reality. To do so, it studies the theatrical experience proposed by Proyecto Prometeu and Testigo de Las Ruínas, coordinated by the colombian group Mapa Teatro. We pretend to raise some considerations on the aesthetic and ethical presuppositions written into these theatrical projects, whose original creative impulse was to as stimulate discussions related to the expropriation suffered by residents of the presently extinguished neighborhood of Santa Inês, by drawing on the impressions, memories and personal reports of former residents. This paper examines specifically the ways and goals of the use of personal narratives of former residents in constructing the scenic actions of these performances.

Key-words: Mapa Teatro. Fiction. Autobiography. Documentary Theater. Memory.

\footnotetext{
* Mestranda do Programa de Pós Graduação em Teatro da Universidade do Estado de Santa Catarina (UDESC). Florianópolis.SC.Brasil.E-mail: heloisa_marina@hotmail.com

** Professor no Programa de Pós-Graduação em Teatro da Universidade do Estado de Santa Catarina (UDESC). Florianópolis.SC.Brasil.E-mail: stephao08@yahoo.com.br
} 
O grupo Mapa Teatro é um coletivo teatral colombiano, sediado na cidade de Bogotá. Seus trabalhos, em geral, buscam relacionar diferentes disciplinas, constituindo formas hibridas de experiências artísticas. A grande maioria das criações do grupo explora um diálogo que cruza ações performativas com elementos documentários e cenas que representam uma realidade ficcional. Essa característica de suas composições nos pareceu um exemplo interessante para refletir sobre o uso de autobiografias, como estratégia de articular tensão entre realidade e ficção em explorações cênicas* ${ }^{*}$. Tal reflexão será desenvolvida a partir da referência específica de dois trabalhos do grupo: Proyecto Prometeu e Testigo de Las Ruínas. Para tanto iremos, primeiramente, realizar breve contextualização sobre a inserção dos trabalhos mencionados na trajetória do grupo, seguida de uma descrição pontual dos mesmos.

Em abril de 2011 Mapa Teatro realizou uma ocupação no SESC-Pompeia, em São Paulo, através do MIRADA**. Esta ocupação incluiu a exibição de três obras teatrais de seu repertório, exposição dos 25 anos de história do grupo e um dia de debates conduzidos por professores universitários, brasileiros e colombianos, estimulados pela temática contida em cada peça que o grupo apresentou em São Paulo na ocasião.

Através do contato estabelecido com os diretores do Mapa Teatro, os irmãos Heidi e Rolf Abderhalden, em São Paulo, tomamos ciência de que os dois trabalhos que estávamos investigando faziam parte de uma ação artística de maior amplitude, o Proyecto $C^{\prime}$ úndua, desenvolvido pelo Mapa Teatro entre os anos de 2001 e 2005. Proyecto C'úndua se constituiu como projeto interdisciplinar, gerando uma serie de ações e composições artísticas das quais participaram, além dos integrantes do Mapa Teatro, os moradores de um bairro de Bogotá, hoje extinto, que se chamava Santa Inês, porém mais conhecido como El Cartucho. O projeto começou a ser desenvolvido justamente por causa do processo de extinção de El Cartucho, que, segundo o grupo, se deu em função da política de renovação do centro de Bogotá*** (Abderhalden, 2010)

El Cartucho, um bairro marginalizado e com problemas sociais semelhantes aos de diversas favelas brasileiras (elevados índices de violência e criminalidade, local onde por vezes existem "poderes" e leis "paralelas", os quais regem as condutas sociais), era também um bairro histórico, com arquitetura de 1830. Depois que a população mais abastada migrou para outras regiões da cidade as casas se deterioraram, foram ocupadas por pessoas de baixa renda e serviam como pensão para os que recentemente haviam migrado a Bogotá, sem emprego e moradia ${ }^{* * * *}$. Nesse local, onde outrora cerca de duas mil pessoas moravam, foi inaugurado em julho de 2002 o parque Tercer Milênio.

A localidade, durante seu processo de "reforma", passou a ser frequentada pelo Mapa Teatro que, neste período, desenvolveu junto a alguns membros da comunidade, uma serie de proposições artísticas. A sede do Mapa Teatro manteve abertas as portas para os moradores desapropriados que demonstrassem interesse de, através da arte, refletir sobre seus processos de perda e de mudança referentes à situação a qual estavam sendo submetidos.

Acerca de propostas artísticas que exploram entrelaçamentos entre o real e o ficcional e sobre impacto destas no espectador, ver, entre outros, Cornargo, Finter e Sánchez.

Evento de teatro que promove de dois em dois anos o Festival Ibero-Americano de Artes Cênicas de Santos (realizado pela primeira vez em setembro de 2010). Durante o intervalo de tempo entre uma edição e outra são realizadas em São Paulo ocupações (como essa feita pelo Mapa Teatro no SESC-Pompéia) de grupos ibero-americanos, nas quais eles apresentam espetáculos do repertório, realizam debates e exposição de trabalhos.

*** Além dos dois trabalhos sobre os quais pretendemos debruçar nossas reflexóes, fizeram também parte do Proyecto C'úndua a instalação realizada na sede do grupo: Re-corridos e a vídeo instalação sonora La limpieza de los establos de Augías, realizada no lote do antigo bairro Santa Inês e, simultaneamente, no Museu de Arte Moderna de Bogotá. Disponível em http://www. mapateatro.org. Acesso: 20/05/201 1).

**** TAYLOR, Diana. Witness to the Ruins, Mapa Teatro. Arquivo pessoal de Rolf Abderhalden, Mapa Teatro, 
O primeiro trabalho a ser descrito neste artigo foi apresentado apenas duas vezes, uma em 2002 e outra em 2003. De modo que para discorrer sobre este foi necessário nos basearmos em estudos escritos sobre o mesmo e, principalmente, em material vídeo-documentado. Ou seja, as reflexões foram feitas a partir do DVD com gravações do espetáculo, concedido a nós pelo grupo.

Tendo em vista que tivemos a oportunidade de assistir presencialmente o segundo trabaIho, Testigo de Las Ruínas, tomaremos essa experiência como referência principal para apreciação.

Proyceto Prometeu, histórias pessoais em face de um confronto social

Para o grupo Mapa Teatro este trabalho é definido como uma Instalação Teatral que se apresenta "como documento de registro" da situação de desapropriação vivida pelos moradores do bairro Santa Inês***** Foi o primeiro trabalho desenvolvido pelo grupo dentro do Proyecto $C^{\prime}$ úanda e contou com duas fases: Prometeo ler Acto e Prometeo: $2^{\circ}$ Acto.

A apresentação ocorreu apenas duas vezes, com espaço de um ano entre uma realização e outra. Em cena se apresentavam ex-moradores do bairro, orientados a seguir um roteiro simples de ações sem grandes preocupações quanto à precisão e perfeição na execução das mesmas. Essas ações eram realizadas simultaneamente por eles e deveriam se relacionar com algum aspecto de suas vivências particulares em El Cartucho. Uma menina, por exemplo, subia e descia de sua cama, um palhaço, também morador, fazia algumas mágicas, um casal conversava sentado em volta de uma mesa.

A primeira fase, Prometeo ler Acto, tomou como ponto de partida o Mito Prometeu na versão do dramaturgo alemão Heiner Müller. Rolf Abderhalden, diretor do grupo, relata em seu ensaio El artista como testigo: testimonio de un artista (2010) que a motivação de partir do mito na condução desse processo artístico, que buscava refletir sobre o "esquecimento de uma memória urbana", se deu pelo fato de o mito ser uma forma de narração que se vale da oralidade como memória. Para Mapa Teatro era justamente a oralidade (dos moradores) o material primordial com o qual podiam contar na ânsia de preservar alguma reminiscência daquele local histórico.

O mito é o relato por excelência. Sua natureza originária faz dele um potenciador de relatos; estes se repetem como os sonhos, configurando-se e desconfigurando-se continuamente numa estrutura móvel que sempre se vivifica. Os relatos da comunidade eram para nós uma parte substancial da arquitetura da memória do bairro. Uma forma de resistência perante o esquecimento, um possível rastro entre as ruínas. (Abderhalden, 2010) $)^{* * * * *}$

Além disso, Abderhalden afirma neste ensaio que para o Mapa havia uma correlação entre a história e as imagens do mito Prometeu de Müller e a experiência pela qual passava o bairro El Cartucho (tomando o bairro tanto como local histórico, quanto como espaço onde se processam relações humanas). O diretor conta que, no texto de Müller, na hora de sua liber-

\footnotetext{
***** Disponivel em http://www.mapateatro.org. Acesso: 20/05/2017).

****** Disponível em

http:/artesescenicas.uclm.es/archivos_subidos/textos/304/El_artista_como_testigo_RolfAbderhalden.pdf, Acesso em 30/09/2011. No original: El mito es el relato por excelencia. Su naturaleza originaria hace de él un potenciador de relatos; estos se repiten como los sueños, configurándose y desconfigurándose continuamente en una estructura móvil que siempre se vivifica. Los relatos de la comunidad eran para nosotros una parte sustancial de la arquitectura de la memoria del barrio. Una forma de resistencia ante el olvido, una posible huella entre las ruinas.
} 
tação Prometeu sente medo, pois está acostumado com a situação de exílio a que foi imposto (2010). Esse medo e insegurança perante a possibilidade de uma liberdade desconhecida pareceu, aos coordenadores do Mapa Teatro, uma premissa interessante de ser explorada frente à circunstância de desmonte que se encontrava o bairro e que obrigava seus moradores a vivenciar uma nova situação, uma "liberdade" desconhecida.

O grupo propôs, então, aos moradores de El Cartucho, que fizessem suas próprias interpretações do mito a partir da versão de Müller:

Abandonar El Cartucho representava para muitos moradores a possibilidade de uma libertação e, ao mesmo tempo, de um desterro. Assim chegamos ao lugar: com a intenção de propor a um grupo de moradores do bairro leituras possíveis deste mito (Abderhalden, 2010)

Essas falas do diretor de Mapa Teatro são importantes, pois destacam que a instalação teatral buscou evidenciar a relação ambígua dos moradores de El Cartucho com o bairro, favorecer o entendimento de que não existia uma verdade objetiva e universal, compartilhada por todos os moradores no que diz respeito à mudança que vinham sofrendo. $O$ projeto do grupo colombiano, segundo as falas de Abderhalden, visava tornar perceptível e sensível os possíveis ganhos e perdas produzidas por esse processo urbanístico na vida dos moradores, bem como interrogar a visão unilateral e progressista, apresentada nas grandes mídias de Bogotá, com relação a transformação do bairro.

O trabalho desenvolvido a partir do conto de Müller foi aberto para exibição depois de um ano. O público que compareceu à apresentação era composto tanto por outros ex-moradores do Santa Inês quanto por pessoas da cidade, como funcionários públicos e até mesmo o prefeito. Na realização do ler Acto havia algumas construções que ainda não tinham sido demolidas.

Prometeo: $2^{\circ}$ Acto, a segunda fase do projeto, aconteceu um ano depois, quando então já não existia mais casa alguma de pé, o processo de demolição já havia terminado e o terreno estava sendo preparado para a construção do Parque Tercer Milênio. Para suprir a falta material que a ausência das moradias deixara, os coordenadores do projeto sugeriram aos moradores que trouxessem ao antigo bairro alguma mobília do cômodo que para eles fosse o mais significativo de suas casas.

Esta instalação teatral foi, então, apresentada em um grande terreno vazio. No espaço onde, outrora, estavam localizadas as casas desse bairro pobre, que alimentava o imaginário social da cidade como local marcado pela violência, prostituição, pelo tráfico de drogas, local do "medo", segundo as memórias do próprio diretor do Mapa Teatro. É natural que fosse também um bairro marcado pela vida cotidiana e corriqueira dos moradores que ali antes residiam.

No dia em que instalação teatral iria acontecer, a localidade tinha o simples aspecto de um gigante terreno baldio, chão de areia. Alguns dos antigos moradores estavam presentes neste local quando, ainda dia, um caminhão surge e começa a descarregar algumas mobilhas nesse descampado.

Nesse espaço, que em função da política de "limpeza" e renovação do centro de Bogotá deixou de ter casas e moradores, armou-se, lentamente, algo que não está claro se poderia ser chamado de palco, picadeiro ou salão de baile. Difícil descrever ao certo, mas sem dúvida pode-se dizer que ali configurou-se, por algumas horas, um espaço poético e estético que se 
confrontava com a realidade pragmática a que remetia.

O definimos como estético pois foi cenograficamente pensado e planejado, local no qual seriam realizadas ações ensaiadas. Mas também pragmático, pois se tratava do local onde realmente viveram aqueles que se apresentariam em cena. A percepção desse cruzamento de ficção e realidade podia também contaminar a cidade de Bogotá, pois no horizonte, ao fundo, se via as luzes reais da cidade, que remetiam o espectador tanto à cidade como dotada de qualidades poéticas quanto à cidade que direciona e modula relações sociais pragmáticas..

Ao assistirmos à gravação desse evento cênico nos perguntávamos se estes móveis escolhidos pelos ex-moradores não estariam posicionados exatamente no local onde, anteriormente, eles eram de fato acomodados. Tratava-se de penteadeiras, camas, mesas de jantar, sofás: móveis de uso real dos moradores desapropriados. Uma singela arquibancada, posicionada a frente dos móveis, foi armada, aparelhagem de luz e som instalada. No alto, atrás desses insólitos móveis, estavam instalados dois telões de cinema.

Os donos da mobília, os antigos moradores do bairro, estavam presentes, vestidos com roupas de gala. Realizariam uma festa? Em volta dos móveis estavam enfileirados uma serie de pequenos e improvisados castiçais, velas e fogo espalhados pelo chão. Traziam alguma espécie de luz e calor a esse ritual que não se saberia dizer bem se era fúnebre ou de passagem, em todo caso, sim, poderíamos chamá-lo de um ritual de despedida.

Essas figuras em trajes de festa que se movimentavam pela cena não diziam palavra alguma durante a realização da instalação teatral, apenas executavam gestos simples relacionados com os móveis e com algum trecho da historia pessoal que tiveram durante o período que viveram em El Cartucho. De fundo ouviam-se suas vozes gravadas, contando anedotas. O público acompanhava as histórias gravadas (o som saía de algum amplificador) ao mesmo tempo em que observavam filmagens que passavam nos telões instalados ao fundo e as ações executadas presencialmente pelos moradores vestidos de gala.

As imagens que eram projetadas no telão, uma espécie de documentação do processo de transformação do bairro, mostravam desde a demolição das casas e pontos emblemáticos do El Cartucho, até coisas corriqueiras como uma mãe falando com um filho, os moradores relatando alguma vivência para câmera, um palhaço fazendo um show. O próprio grupo tem definido da seguinte forma esta instalação teatral:

(...) nos telões se apresentam simultaneamente imagens do bairro (material de arquivo) e seguimentos de histórias de vida dos participantes, que por sua vez inter-atuam com ações e relatos ao vivo. Primer Acto passou pelas histórias de vida e experiência de quinze pessoas. (...) O espaço é uma reconstrução poética dos lugares que uma vez foram habitados. As narrações articuladas com o texto sobre o mito de Prometeu, escrito por Heiner Müller e acompanhadas por um emotivo ambiente sonoro trabalhado ao vivo, terminam em um grande baile, celebração que convida a revisar a forma em que geralmente percebemos este lugar .

A instalação continha, dessa maneira, a proposta de articular as autobiografias dos moradores (fossem estas faladas ou simplesmente realizadas através de ações) como possibilidade de 
expressão de determinada realidade concreta. $O$ espetáculo, que partia das narrativas pessoais daqueles que tinham suas vida relacionadas à história do bairro, explorou tais autobiografias como uma outra possibilidade de discurso sobre a transformação do local. Tratava-se de um discurso que se propunha a revelar realidades diferentes à apresentada pela mídia. Definir o local não por meio de estatísticas, levantamentos sociológicos ou historiográficos, discursos predominantemente objetivos, mas por meio de lembranças pessoais multiplica as características desse espaço e the confere uma duplicidade: a concretude inabalável do processo urbanístico junto da concretude afetiva das histórias pessoais. Desse modo, se articula um duplo olhar crítico, pois o processo histórico perde sua neutralidade e a experiência pessoal perde seu caráter privado. Voltaremos nessas reflexões mais adiante, antes, porém, gostaríamos de descrever a outra apresentação que será analisada neste artigo.

Testigo de las ruínas: imagens ausências, pessoas presenças

Este trabalho, denominado pelo grupo de vídeo instalação, é apresentando através da exibição de um filme-documentário. A produção do filme, poderia-se dizer, foi realizada à maneira clássica: montagem feita a partir da gravação em vídeo do processo de demolição das casas de El Cartucho, da posterior construção do parque Tecer Milênio e de entrevistas com moradores desapropriados, empreiteiros da obra, etc. Definimos como documentário clássico tendo em vista que o tratamento dado às imagens (o modelo de montagem e captação das mesmas) está de acordo com as técnicas tradicionais do cinema documentário, o vídeo não revela seus processos de criação (gravação e montagem), de forma que os documentos são quase sempre explorados pelos seus criadores como dados objetivos.

Há entretanto uma característica particular no modo de exibição desse vídeo que pode ser vista como um estímulo à leitura das imagens apresentadas como uma realidade que é contada e, por tanto, pode transparecer como construída: o filme não é projetado em um telão único e imóvel, mas sim em quatro telões que são móveis. Estes telões são manipulados por artistas do grupo durante a projeção do filme, de forma que o vídeo apresentado se torna fragmentado. Em dados momentos, por exemplo, cada telão mostra um vídeo diferente, em outros a imagem de um telão complementa a do outro (usa-se a técnica de imagem estendida). No decorrer da exibição o grupo vai explorando uma serie infinita de combinações entre as imagens dos quatro telões, duplicação, complementação, repetição, justaposição, etc.

Outra variante explorada nesse trabalho é a presença física desses artistas que, além de aparecerem manipulando os telóes e projetores, interagem com os mesmos e com suas respectivas imagens. Por exemplo, algumas vezes os artistas se colocam atrás do telão, projetando suas sombras nos mesmos, explorando algum tipo de presença (imediata, viva) que contrasta com a imagem gravada.

Paralelamente a tudo isso, o espectador acompanha Juana María Ramírez, ex-moradora do El Cartucho, fazendo arepas ${ }^{* * * * * * *}$ e chocolate quente durante a exibição do vídeo. Esta muIher está posicionada em primeiro plano, a frente dos telões, porém bem no canto do palco. Enquanto as imagens e as entrevistas vão contanto uma narrativa sobre a destruição do bairro, Juana Ramírez realiza em cena a atividade econômica que exercia quando morava em El Cartucho. No fim do espetáculo convida todos a saborearem seus quitutes. 
O grupo colombiano, em seu site oficial, define esta obra sua:

Testigo de las Ruinas é uma obra que transita entre a vídeo instalação e o teatro-documental. Sintetiza de maneira não-cronológica nem linear a experiência de Mapa Teatro no processo de desaparecimento de um bairro emblemático da cidade de Bogotá: Santa Inés - El Cartucho e o aparecimento de um parque nesse mesmo local, através das imagens e sons mais evocativos desse processo. Não há atores no sentido tradicional, mas artistas performáticos que manipulam quatro telas e quatro vídeo-projetores no espaço contribuindo, através de uma coreografia, para o significado dramático das histórias de antigos habitantes do bairro e de trabalhadores que construíram o parque. Através da experiência pessoal e ao mesmo tempo coletiva, lúdica e dramática, os espectadores configuram durante a obra sua própria representação de um mundo distante mas inquietantemente próximo e familiar ao mesmo tempo. Nem documentário, nem crônica jornalística ou registro sociológico, Mapa reitera seu interesse em plasmar, até o final, sua experiência como testemunha através do gesto artístico.

Nesse trabalho, portanto, apresenta-se uma evocação sugestiva, uma espécie de recriação, por meio de procedimentos estéticos, do processo de demolição do bairro. Esta recriação, configurada através de imagens, coincide com a ausência das pessoas que viveram tal processo. Essa ausência não passa despercebida nem deixa de ser interrogada pelos criadores da obra, já que os mesmos propõem ao público compartilhar a presença real de pelo menos uma ex-moradora, que se faz presente em cena durante toda a apresentação.

Esta função desestabilizadora aparece de forma parecida em Proyecto Prometeu, através do contraste entre o silêncio dos moradores e seu traje de gala (a festa é de quem? Para quem serve? De quem será a futura diversão? A que remete o silêncio forçado ou imposto dos antigos moradores?)

Das possíveis contradições que se processam entre realidade e ficção em Proyecto Prometeu e Testigo de Las Ruínas

Gostaríamos de, a partir da descrição desses dois trabalhos do grupo Mapa Teatro, refletir sobre as características de como são apropriadas, nessas apresentações, as autobiografias, de que maneiras esta apropriação permite desencadear confrontos entre aspectos reais e ficcionais da cena e quais reflexões, reverberações intentam suscitar naqueles que compartilham o evento.

Para tanto, destacamos também as imagens e discursos criados pelas mídias e pelos representantes políticos da cidade, acerca do processo do progresso, como elemento de confronto entre o campo ficcional e real, tendo em vista que em ambos os trabalhos a presença dos ex-moradores e da ex-moradora questiona não só as imagens filmadas pelo grupo, mas dialoga criticamente com os discursos midiáticas da limpeza social de uma área subdesenvolvida.

\footnotetext{
*********(Disponivel em http://www.mapateatro.org. Acesso: 25/05/201 1). No original: Testigo de las Ruinas es una obra que transita entre la video-instalación y el teatro documental. Sintetiza de manera no-cronológica ni lineal la experiencia de Mapa Teatro en el proceso de desaparición de un barrio emblemático de la ciudad de Bogotá: Santa Inés - El Cartucho y la aparición de un parque en ese mismo lugar, a través de las imágenes y los sonidos más evocadores de éste proceso. No hay actores, en el sentido tradicional, sino performeros que manipulan cuatro pantallas y cuatro video-proyectores en el espacio contribuyendo, a través de una coreografía, a la significación dramática de los relatos de antiguas habitantes del sector y de obreros que construyeron el parque. A través de una experiencia personal y al mismo tiempo colectiva, lúdica y dramática, los espectadores configuran a lo largo de la obra su propia representación de un mundo lejano pero inquietantemente próximo y familiar a la vez. Ni documental, ni crónica periodística, ni registro sociológico, Mapa reitera su interés de plasmar, hasta el final, su experiencia como testigo a través del gesto artístico.
} 
As imagens exibidas nos telões, em ambos os trabalhos, assim como as ações simples executadas pelos moradores (subir e descer da cama, cozinhar arepas), exploravam cenicamente acontecimentos corriqueiros que se repetiam no dia a dia do bairro. A narrativa dessa outra face do cotidiano do bairro se desloca, pelo menos em parte, da reiteração das imagens de violência e horror tão comumente associadas a este local.

Em vista dessas escolhas, nos parece que a preocupação maior em ambos os projetos do grupo Mapa Teatro era solapar os argumentos sobre o processo do progresso nas mídias estabelecidos, questionando as verdades contadas através desses meios de comunicação. Ou seja, o grupo se ocupou de dar voz àqueles sujeitos aos quais a mídia renegara tal espaço, ainda que fossem os que diretamente se afetariam pela renovação do bairro.

A partir disso, nos perguntamos o que seria mais importante nessas duas propostas artísticas: marcar o real em contraste ao ficcional, ou marcar a perda de um real? Acreditamos que o grupo colombiano criou um tipo de ritual de lamentação ou despedida que se baseava na evocação desse real perdido (a moradia naquele lugar).

Partindo da pergunta e constatação acima feitas, tomaremos as características que orientam criações de teatro documentário para realizar a análise. Teremos em conta, também, que nos trabalhos descritos aparece como primordial a descontração da noção de personagem (que é acentuada pelo fato dos protagonistas das instalações se auto-representarem e por não serem atores de profissão). Ou seja, pela conformação do deslocamento de uma estratégia representacional (criar um personagem que fala e atua em nome ou por alguém) para uma estratégia performativa (deixar que os antigos moradores atuem, ainda que em silêncio, em nome próprio).

O termo Teatro Documentário foi proposto na década de 1960 pelo dramaturgo alemão Peter Weiss. A pesquisadora lleana Diéguez esclarece que:

Weiss propôs o Teatro Documentário como àquele que se ocupa "exclusivamente da documentação de um tema" (99), expondo informações através de atas, carta, declarações, alusões, entrevistas, reportagens, manifestações de personalidades conhecidas, fotografias, documentos cinematográficos, os quais deveriam estar dispostos no cenário sem variar o seu conteúdo. Propõe a técnica de montagem para ressaltar detalhes e apresentar os feitos a juízo. Não trabalha com personagens nem com descrições de ambientes. Busca desviar-se dos módulos estéticos do teatro tradicional e põe em discussão seus próprios meios. Ainda que tente certa liberação do marco artístico provocando uma tomada de posição frente aos feitos, Weiss entendia o Teatro Documentário como um feito artístico. (99-110) (...) O Teatro Documentário na perspectiva de Weiss, representa uma ação contra as situações presentes. $(102)^{* * * * * * * *}$ (Diéguez, 2007, p. 85-86)

\footnotetext{
********NNo original: Weiss propuso el Teatro Documentario como aquel que se ocupa "exclusivamente de la documentación de un tema" (99), exponiendo informaciones a través de actas, cartas, declaraciones, alocuciones, entrevistas, reportajes, manifestaciones de personalidades conocidas, fotografías, documentales cinematográficas, los cuales debían disponerse en el escenario sin variar su contenido. Propone la técnica de montaje para resaltar detalles y presentar los hechos a dictamen. No trabaja con caracteres ni con descripciones de ambientes. Busca desviarse de los módulos estéticos del teatro tradicional y pone en discusión sus propios medios. Aunque intenta cierta liberación del marco artístico provocando una toma de posición frente a los hechos, Weiss entiende el Teatro Documento como un producto artístico. (99- 1 10). El teatro documento en La perspectiva de Weiss, representa una acción contra las situaciones presentes. (102).
} 
Pensando nessa perspectiva de Peter Weiss sublinhada por Diéguez, de que o teatro documentário se concretiza como ação ou resistência a uma dada situação, pode-se dizer que tanto Proyecto Prometeu como Testigo de Las Ruínas são trabalhos artísticos que estão amparados em tal pressuposto. Não apenas por serem uma forma de resistência artística a determinadas políticas públicas adotas pelo governo de Bogotá, como também pelas características de sua composição poética: apropriação de relatos (narrados ao vivo ou gravados) feitos pelos próprios indivíduos afetados por tal política, exploração estética de documentos relacionados à destruição do bairro (imagens filmadas, fotografias, etc).

Se, porém, nos anos sessenta, década em que Weiss postulou as concepções do teatro documentário, este partia, tendencialmente, do princípio de que a dimensão social abarcava o sujeito, deixando pouco espaço para uma concepção individual e subjetiva do mesmo (DIP, 2005), no trabalho do grupo colombiano esta posição já não aparece de forma tão fechada. Ainda que este trabalho se preocupe em problematizar dada conformação social, não deixa de ser uma composição artística que explora uma visão singular do sujeito.

Tendo em vista que os protagonistas das cenas não contam outras histórias ou encenam outras ações que as suas mesmas, o palco passa a revelar não apenas verdades históricas mas também individuais. Em Prometeu, além da narração de histórias próprias, o uso da mobília pessoal como cenografia acentua esta característica, já que não há nada mais privado que o interior da própria casa, "aberta", simbolicamente, ao público nesta instalação. A presença real, em Testigo de Las Ruínas, de uma ex-moradora do bairro, que em cena não faz mais que realizar a atividade econômica que desenvolvia quando morava em El Cartucho, também acentua esta valorização da subjetividade nos trabalhos mencionados.

Nos dois trabalhos descritos verifica-se o uso de narrativas pessoais em cena como estratégia para uma composição artística que objetiva contestar uma dada ordem social. Ao grupo colombiano, portanto, uma questão que aparece como crucial é a reflexão política e social que buscam promover por meio da arte, justamente uma das perspectivas do teatro documental dos anos sessenta e setenta.

Porém, no caso dos espetáculos descritos, o sujeito singular é trazido a cena. É ele mesmo quem se mostra, quem narra ou age, segundo sua própria experiência pessoal. Mas estas narrativas pessoais expandem o campo privado e se transformam, por meio da instalação teatral, em uma experiência compartilhada. Tal compartilhamento se dá, primeiramente, entre os próprios participantes da montagem teatral e, em um segundo momento, entre moradores e espectadores. Os moradores começam a dividir com os espectadores simbolizações de suas experiências.

O grupo colombiano, nesse sentido, não tomou o tema da desapropriação de moradias como mote para a composição de um espetáculo documentário. Essa composição se deu através do encontro com pessoas que tinham experiências íntimas a serem dividas. $O$ trabalho ganha força pois não se configura simplesmente como um discurso contra determinada ordem política, mas apresenta pessoas que compartilhavam em cena uma parcela de sua intimidade, agregadas, nesse caso, a uma história socialmente problemática.

Dessa forma pode-se afirmar que, em alguma medida, o trabalho do Mapa Teatro busca respeitar o que muitas propostas de teatro documental dos últimos anos têm adotado: uma postura cuidadosa no processo de criação artística, que não renegue aos indivíduos afetados pela situação tematizada o direito à voz, a auto interpretação dos episódios apresentados. Como destaca o pesquisador espanhol José Sánchez 
(...) as práticas participativas e metodológicas de criação coletiva na América Latina ensaiaram atualizações do teatro político das vanguardas, mas ampliando procedimentos que evitavam a soberba dos artistas em sua relação com povo: camponeses, operários e indígenas se convertiam em personagens, coautores, espectadores e às vezes atores das peças. (...) Para evitar a apropriação de uma dor que é de outros, para alijar o risco da identificação e da muito mais perigosa compaixão que utiliza o sofrimento alheio em beneficio próprio e fazer justiça mediante o testemunho, a análise e a memória. (Sánchez, 2007)

Esta postura pode ser verificada em Prometeu, por exemplo, tendo em vista que os espectadores puderam vivenciar uma encenação na qual ao invés de assistirem atores representando certos personagens baseados em fatos reais, estavam diante de protagonistas que de fato eram as mulheres e os homens que viveram a situação cenicamente problematizada.

Ao evitar que a cena apresente uma visão generalizada dos ex-moradores, onde as questões sociais referentes à desapropriação apagariam os problemas, sonhos, medos e desejos individuais dos mesmos, ou seja, suas subjetividades, estes têm a oportunidade de se apresentarem fora dos clichês e preconceitos socialmente estabelecidos para os moradores de El Cartucho. E, nesse sentido, Proyecto Prometeu propõe que se estabeleçam aproximações mais complexas e menos taxativas no que diz respeito às relações humanas e sociais do antigo bairro do que as exploradas pelas mídias.

O uso dinâmico de quatro telões, em Testigo de Las Ruínas, aparece com uma função semelhante: fugir de uma visão ou representação homogênea do processo de transformação do bairro. A exibição do filme, que documenta a demolição das casas de El Cartucho, realizada de forma fragmentada, sugere que há interpolações nas narrativas que contam essa história e que não seria pertinente interpretar tal processo a partir de um ponto de vista único, sólido e imóvel. A presença de Juana Ramírez, fazendo arepas, surge ainda como mais uma possibilidade de narrativa sobre a transformação do bairro. Denota também uma preocupação, por parte do grupo, em evitar que a dor, ou o processo alheio de perda, se tornasse apenas suporte para a criação artística, sem que esta se atrelasse àqueles que vivenciaram tal processo.

João Moreira Salles, ao ponderar sobre as perspectivas contemporâneas do documentarismo no cinema, argumenta que

(...) nos últimos anos, o cinema documental vem tentando encontrar modos de narrar que revelem, desde o primeiro contato, a natureza dessa relação. São filmes sobre encontros. Nem todos são bons, mas os melhores tentam transformar a fórmula eu falo sobre ele para nós em eu e ele falamos de nós para vocês. (...) não pretendem falar do outro, mas do encontro com o outro. São filmes abertos, cautelosos no que diz respeito a conclusões categóricas sobre essências alheias. Não abrem mão de conhecer, apenas deixam de lado a ambição de conhecer tudo. (Salles, 2005)

Essa fórmula narrativa por ele defendida, não aparece tão claramente no trabalho do Mapa; não se evidencia de quem foi a escolha com relação à configuração estética e a montagem final de Prometeu e de Testigo, nem tampouco como se deu o encontro entre o grupo e a comunidade.

Embora o grupo cite, na descrição de Testigo de Las Ruínas, que esta obra "sintetiza a experiência de Mapa Teatro no processo de desaparecimento do bairro" (op. cit.), não fica expli- 
citado ao espectador como se deu o encontro entre artistas e moradores. $O$ elenco do grupo está sempre nos bastidores, e mesmo em Testigo quando manipulam os telões, esse gesto não chega a revelar como se processou, de fato, o encontro entre esses dois distintos grupos sociais (artistas e moradores). Talvez, o que possa ser dito, é que a manipulação dos telões sugere que há uma interferência de um grupo sobre o outro. Mas as contradições desse encontro não são problematizadas da mesma forma como são os discursos midiáticos acerca do bairro.

O campo ficcional, nos trabalhos coordenados pelo Mapa Teatro, está localizado nas imagens criadas pelas mídias acerca do processo do progresso, da limpeza social dessa área subdesenvolvida (ou seja, está fora do evento artístico). A presença real dos moradores questiona e dialoga criticamente com tais imagens como uma verdade que questiona a ficção midiática sem questionar, todavia, sua própria parcela ficcional.

Assim, na experiência do Mapa Teatro com o bairro, a ausência dos artistas, ou da explicitação do encontro entre estes e os moradores, na forma cênica que atinge, tem a tendência de artificializar a versão da mídia e de naturalizar a versão teatral. Aparentemente o arranjo cênico não tinha como preocupação defender uma verdade sobre El Cartucho, mas aparece um certo descompasso entre a intensão do grupo e a realização artística. A articulação de materiais documentários, de autobiografias com elementos teatrais e meta teatrais, por si só não garantiu que fosse revelado o olhar dos artistas sobre o processo, embora não há como suspeitar que ele não se encontre, de alguma forma, refletido nas instalações descritas.

Dessa forma, as narrativas pessoais, nos trabalhos citados, estabelecem uma reflexão a respeito da política de despejo adotada pelo município de Bogotá que por um lado valoriza a subjetividade daqueles que a vivenciaram, mas por outro não evidenciam a (inevitável) dimensão ficcional que o próprio projeto artístico também carrega. Localizam, portanto, a ficção nos discursos das autoridades sobre a situação no bairro, sobre a necessidade do despejo para o progresso. Contra essa ficção evocam a presença de uma subjetividade concreta: a da testemunha, criando um tipo de ritual de lamentação que se baseia na evocação desse real perdido, mas que não foca a problemática epistemológica.

\section{Referências}

ABDERHALDEN, Rolf. El artista como testigo: testimonio de um artista. 2010. Disponível em http://artesescenicas.uclm.es/archivos_subidos/textos/304/El_artista_como_testigo_RolfAbderhalden.pdf, acesso: 30/09/2011.

DIÉGUEZ, lleana. Escenarios liminales. Buenos Aires: Atuel, 2007.

DIP, Nerina. Espetáculo solo, fragmentação da noção de grupo e a contemporaneidade. 2005. Disponível em http://www.tede.udesc.br/tde_arquivos/2/TDE-2007-03-27T140246Z-311/Publico/NERINA\%20DISSERTACAO.pdf, acesso: $\overline{15} / 01 / 2011$.

SALLES, João Moreira. A dificuldade do documentário, in: Martins, José Souza; Eckert, Cornelia; Caiuby Novaes, Sylvia (orgs.) O imaginário e o poético nas ciências sociais. Bauru: EDUSC, 2005.

SÁNCHEZ, José. Prácticas de lo real en la escena contemporánea. Barcelona: Visor Libros, 2007. 